\title{
ENTRE MARTINHO LUTERO E PAULO FREIRE: PEDAGOGIAS PERTINENTES
}

\section{BETWEEN MARTINHO LUTERO AND PAULO FREIRE: RELEVANT PEDAGOGIES}

\author{
Everaldo Fernandes da Silva ${ }^{1}$ \\ William Francisco da Silva ${ }^{2}$
}

\section{RESUMO}

Este artigo, resultado de uma pesquisa de mestrado na área de Educação, enseja distinguir e aproximar de forma dialógica as pedagogias Luterana e Freireana. Não obstante, o distanciamento espaçotemporal entre ambos, com as especificidades contextuais, materiais e simbólicas, situamos aspectos relevantes em suas empreitadas educativo-políticas. Para tanto, utilizamo-nos da pesquisa bibliográfica de natureza qualitativa para alcançarmos o objetivo dessa investigação.

Palavras-chave: Martinho Lutero; Paulo Freire; Pedagogias.

\section{ABSTRACT}

This article is the result of a masters research in the area of Education and it distinguishes and approaches in a dialogical way the Lutheran and Freirean pedagogies. Nevertheless, the space-time distance between the two, with the contextual, material and symbolic specificities, places relevant aspects in their educational-political works. To do so, we used bibliographic research of a qualitative nature to reach the objective of this investigation.

Keywords: Martin Luther. Paulo Freire. Pedagogies

\section{INTRODUÇÃO}

O presente artigo é fruto de uma parte da dissertação do mestrado em Educação Contemporânea, concluída recentemente. Tal investigação objetivou conhecer e analisar alguns aspectos relevantes do pensamento luterano que traduzem a sua ideia de educação. Da

\footnotetext{
${ }^{1}$ Doutor em Educação. Professor adjunta da UFPE - CAA. E-mail: everaldofernandes.silva@gmail.com

${ }^{2}$ Mestre em Educação Contemporânea. Técnico em educação da Secretaria de Educação de Riacho das Almas PE. E-mail: william2007silva@,hotmail.com
} 


\section{Revista \\ Debates Insubmissos}

mesma forma com Freire, ressaltando suas possíveis aproximações com as ideias embrionárias e revolucionárias do Reformador acerca da educação.

Com esta investigação, alvitrou-se um diálogo aproximativo entre a Educação Luterana e a Educação Popular como fonte inspiradora para uma melhor compreensão de práxis pedagógica tecida pelos atores de uma instituição não-escolar no agreste pernambucano. As abordagens epistemológicas foram representadas, prioritariamente, por dois de seus expoentes: Martinho Lutero e Paulo Freire. Aqui, detemo-nos à empreitada de estabelecer um diálogo entre as pedagogias destes dois autores, elegendo algumas categorias, como um mapa de referências, que foram possibilitadoras de maior lucidez sobre as pedagogias engendradas pelos referidos autores.

No intento de encontrar luzes para a compreensão teórico-metodológica, elucidamos, a princípio, alguns pontos de mutualidade e de complementaridade em que a Educação Luterana e a Educação Popular parecem ajudar-se reciprocamente e, assim, ampliar a nossa concepção dos processos aprendentes e ensinantes nas diversas ambiências sociais. E, posteriormente, discorremos acerca de categorias nucleares provenientes do pensamento dialético-hermenêutico de Lutero e Freire com o intuito de clarear possíveis estruturantes da práxis pedagógica desenvolvida em espaços educativos não-escolares.

Salvaguardadas as devidas proporções de tempo e espaço, enxergamos possíveis aproximações entre o pensamento educacional de Lutero e a pedagogia de Freire. Vale salientar que tanto Lutero quanto Freire estava enraizado num tempo, em contextos diferentes e tratando de educação com públicos diversificados e cosmovisões distintas. Mesmo assim, notórias são as contribuições desses autores para a sistematização de um modelo educacional mais humano e igualitário em meio às peculiaridades sociopolíticas e espaço-temporais.

Podemos constatar simultaneidades, a partir dos cenários distantes, nos quais se instauram: a Reforma Protestante e a Educação Popular. A primeira, de modo crítico, denuncia os abusos da corte religiosa romana com relação às práticas exploradoras de simonias e a própria crise da escolástica, evocando um novo jeito de se fazer educação, mais aberto, menos punitivo e repressivo, e que estivesse voltado para todos, inclusive os empobrecidos da Alemanha. A segunda, emerge em meio aos movimentos civis e de lutas por 
uma educação que levasse em conta as necessidades dos mais pobres e marginalizados da sociedade; como instrumento de conscientização, encabeça a luta pela democratização do saber escolar, a inclusão de povos subalternizados nos espaços escolares e o reconhecimento dos saberes prévios acumulados pelos/as educandos/as.

\section{EDUCAÇÃO EM MARTINHO LUTERO}

Como prenunciado, a primeira parte deste artigo pretende estabelecer uma relação dialógica acerca das pedagogias de Lutero e de Freire. Cada uma delas carregada de sentidos, as quais contribuíram e continuam a corroborar com as compreensões de Educação na contemporaneidade. A pedagogia de Freire bastante conhecida e referendada, já a de Lutero pouco referendada e bastante desconhecida nas literaturas do pensamento educacional do Brasil. Entretanto, na história da educação, ambas, assumiram um papel extremamente relevante para a instauração de práticas pedagógicas mais abertas e progressistas.

Antes de entrarmos nas questões que nos propomos examinar, faremos duas observações: uma sobre o que compreendemos por pedagogia, outra sobre o lugar de fala de Lutero.

Ao que nos referimos quando falamos de pedagogia luterana e pedagogia freireana? Referimo-nos a processos de construção de teorias da formação humana. Em consonância com João Francisco de Souza, entendemos

\footnotetext{
a Pedagogia não como curso de pedagogia, mas como elaboração de uma teoria da formação humana do sujeito humano. Isso supõe uma teoria da transformação da sociedade (uma reinvenção da emancipação humana), portanto uma teoria da ação coletiva (recognição das ciências sociais/humanas) que se específica ao interagir com os fenômenos econômicos, políticos, culturais, nos quais se incluem os educativos, analisando-os, na busca de identificar suas contradições, conflitos e ambigüidades, mas também suas potencialidades, indicando meios de promovê-las, sendo, nesse processo, permanentemente reelaborada (SOUZA, 2006, p. 40).
}

Essa compreensão de pedagogia fornecida por Souza nos põe em situação confortável para associarmos as contribuições do pensamento teológico de Lutero a uma pedagogia luterana. Entretanto, o lugar de fala do Reformador não é a educação, propriamente dita. Lutero é teólogo e não pedagogo; assim, explica o pastor luterano Davi Haese: 


\section{novist \\ Debates Insubmissos}

Constato que Lutero não quis ser pedagogo, nem reformador da pedagogia. Sendo teólogo, e como tal ele se manifesta sobre questões de educação. Apesar disso friso que a sua contribuição para com a educação é muito valiosa e vale como desafio de reflexão para os dias atuais ${ }^{3}$.

Para melhor compreendermos a pedagogia luterana, faz-se necessário de início, um breve resgate histórico e hermenêutico contributivo dos alcances educacionais desenvolvidos no período da Reforma Protestante na sociedade alemã, chave interpretativa para se ter maior clareza sobre a educação de sua época em diálogo com a contemporaneidade. Assim, retrata Jardilino ao tonificar o legado de Lutero e dos demais reformadores:

relegar o ato educativo desses humanistas apenas à educação cristã retira de nós a possibilidade de compreender as profundas mudanças político-educativas e pedagógicas que propuseram os ideários da Reforma Protestante, as quais abriram uma rachadura no velho edifício educativo medieval a caminho da modernidade (2009, p. 7).

Deste modo, a atribuição à Reforma de um retorno às origens merece destaque não somente no âmbito religioso, mas transcende as ambiências educativas religiosas e este novo modo de pensar o humano, abre veredas para outras leituras de sociedade e educação a partir da tradição bíblica. Por isso, chama-nos a atenção quando da ausência, ou a incipiência de dados consubstanciais sobre o espólio de Lutero e dos outros reformadores do século XVI nos manuais e compêndios de História da Educação, constatação feita por Jardilino (2009) ${ }^{4}$ e também evidenciada por nós, na obra de Dermeval Saviani, intitulada História das Ideias Pedagógicas no Brasil, quando o autor faz uma vaga referência à Reforma, tão somente, com o intuito de ilustrar o objetivo primordial da contrarreforma: "À Reforma protestante, materializada na 'tese luterana da sola scriptura', para a qual a doutrina, em sua pureza original, derivava dos textos originais hebraicos e gregos, a Igreja de Roma moveu tenaz oposição..." (SAVIANI, 2013, p. 46), levando-nos a entender que para a história das ideias pedagógicas, no Brasil, nenhuma contribuição pôde ser extraída da Reforma protestante, nem tampouco do pensamento de Lutero.

\footnotetext{
${ }^{3}$ Trecho de entrevista concedida para fins dessa pesquisa, no dia 19 de dezembro de 2017.

${ }^{4}$ Atentamos para a afirmativa do autor: "Os nossos compêndios de História da Educação dedicaram a essas ideias poucas páginas. Há uma ausência de material mais reflexivo do que foi esse momento na história da Educação" (JARDILINO, 2009, p. 8).
} 


\section{Revista \\ Debates Insubmissos}

Em contrapartida, o italiano Cambi ao analisar os impactos da Reforma protestante, ressalta que a partir do movimento do protestantismo,

[...] afirmam-se em pedagogia o princípio do direito-dever de todo cidadão em relação ao estudo, pelo menos no seu grau elementar, e o princípio da obrigação e da gratuidade da instrução, lançando-se as bases para a afirmação de um conceito autônomo e responsável de formação, não estando mais o indivíduo condicionado por uma relação mediata de qualquer autoridade com a verdade e com Deus (1999, p. 248).

Para se concretizar a reforma tão almejada, Lutero entende uma intrínseca ligação entre Reforma e Educação das crianças e dos jovens. E, ao pensar a educação, não a pensa como fenômeno ilhado, e sim, como uma manifestação humana estabelecida na relação com a sociedade. Daí, sua preocupação com a democratização do ensino. Pessoas educadas e bem instruídas poderiam sustentar e alastrar o pensamento reformador, isto é, apenas à luz da Palavra, sujeitos livres das autoridades eclesiásticas da Igreja obteriam a condição autônoma (emancipada) para construírem a sociedade, como afirma o próprio Lutero:

[...] o progresso de uma cidade não depende apenas do ajuntamento de grandes tesouros, da construção de grandes muros, de casas bonitas, de muitos canhões e da fabricação de muitas armas. Muito antes, o melhor e mais rico progresso para uma cidade é quando ela tem muitas pessoas bem instruídas, muitos cidadãos sensatos, honestos e bem educados. Estes então também podem ajuntar, preservar e usar corretamente riquezas e todo tipo de bens (2000, p. 19).

Entendendo que a produção discursiva do sujeito abarca um mundo de sentidos e significados e que não há consciência que atua fora do mundo, referimo-nos a uma consciência engajada, de um sujeito criado mediante contextos, cujo ser-no-mundo é também ser-ao-mundo, sendo a intencionalidade sua experiência em construção (REZENDE, 1990).

Desta feita, situar Lutero no espaço e tempo implica na compreensão de uma época de transição, como já dissemos, a era medieval entrava em declínio cedendo lugar aos prenúncios da modernidade, ressaltando as tensões pujantes entre a Igreja Católica e o movimento de Reforma, na mesma direção os embates políticos e econômicos na sociedade alemã, sobretudo, as crises na moral e na ética cristãs e a decadência na qualidade da educação oferecida. 


\section{Debates Insubmissos}

Revista

\section{EDUCAÇÃO EM PAULO FREIRE}

Da mesma forma que a pedagogia luterana emerge em meio a um contexto de crise e de reorganização na estrutura social, política e econômica de sua época, a pedagogia freireana é fruto de uma época de profundas mudanças, ou pelo menos, que clamava por transformações, principalmente, de ordem econômica e social. Diante dessa realidade, o educador Paulo Freire associa o processo de libertação dos oprimidos às políticas educacionais e não de programas de alfabetização. Isto é, sem uma educação críticohumanizadora seria impossível pensar na superação de uma consciência ingênua para uma consciência crítica.

De acordo com Saviani (2013) ao discorrer sobre a pedagogia libertadora de Paulo Freire, destaca que é possível detectar no ser social, três níveis de consciência: 1) consciência mágica; 2) transitivo-ingênua e 3) transitivo-crítica. O primeiro nível é peculiar a uma sociedade fechada; e a passagem desse para o segundo nível de consciência, dá-se de maneira automática com a mudança provocada pelo processo de industrialização e urbanização e evoca, mas não efetiva, a participação do povo na vida política; no entanto, a passagem da consciência transitivo-ingênua para a transitivo-crítica não se dá de modo automático, mas a partir de um trabalho educativo voltado, intencionalmente, para a libertação, a emancipação dos sujeitos empobrecidos.

Baseado nessa teoria das transitividades, Freire parte da realidade brasileira, apontando e denunciando, mediante "elementos histórico-antropológicos, as raízes de nossa inexperiência democrática, localizadas na forma como ocorreu a colonização do Brasil" (SAVIANI, 2013, p. 324). Freire propõe, então, uma educação direcionada para a responsabilidade social e política, que encorajasse e desse ao ser humano, condições de empoderamento para discutir e problematizar a sua própria realidade existencial e social.

A mola mestra da educação em Freire é articular uma pedagogia que potencialize a práxis educativa como ferramenta de libertação. Desta feita,

Se a possibilidade de reflexão sobre si, sobre seu estar no mundo, associada indissoluvelmente à sua ação sobre o mundo, não existe no ser, seu estar no mundo se reduz a um não poder transpor os limites que lhe são impostos pelo próprio 


\section{novist \\ Debates Insubmissos}

mundo, do que resulta que este ser não é capaz de compromisso. É um ser imerso no mundo, no seu estar, adaptado a ele e sem ter dele consciência. Sua imersão na realidade, da qual não pode sair, nem 'distanciar-se' para admirá-la e, assim, transformá-la, faz dele um ser 'fora' do tempo ou 'sob' o tempo ou, ainda, num tempo que não é seu (FREIRE, 2008, p. 16).

O processo educativo forjado por Freire necessariamente estabelece uma conectividade com a contextura da sociedade a que se aplica. Sem esse diálogo entre ser humano e mundo não há comprometimento histórico, não há como se transformar nada e nem tampouco "esperançar" uma realidade nova e surpreendente, isto é, o "inédito viável”. Nesse sentido, é tarefa primordial da pedagogia freireana fazer emanar no humano o profundo ato de alfabetizar a existência, no sentido que, "aprender a ler é aprender a dizer sua palavra. E a palavra humana imita a palavra divina: é criadora” (SAVIANI, 2013, p. 329).

Essa abertura humana para compreender o mundo e compreender-se junto ao mundo é que torna possível ao ser humano realizar sua vocação ontológica de ser mais. Para essa direção nos aponta, Calado:

Os humanos, como seres de relação ontologicamente vocacionados a ser mais, não se contêm no seu pedaço, e sentem-se, ipso facto, arrastados pela curiosidade e pelo gosto da aventura a contemplar outras paisagens, pois, se se fecham em seu mundo, correm o risco de sentirem-se de tal modo próximos do mundo natural, que se sentirão antes parte dele do que como seus transformadores $(2001$, p. 34) [grifo do autor].

O que nos chama maior atenção nessa discussão é compreender que a natureza relacional humano-mundo assume uma função genuinamente social: reinventar a educação. $\mathrm{Na}$ medida em que o ser histórico toma consciência de suas potencialidades inventivas e criativas, sua existência oportunamente passa a ser no e com o mundo, enchendo-o de sentidos e significados. "O mais importante nesta palavra, 'reinventar', é a ideia de que a educação é uma invenção humana e, se em algum lugar foi feita um dia de um modo, pode ser mais adiante refeita de outro, diferente, diverso, até oposto" (BRANDÃO, 2013, p. 103). Naturalmente, essa afirmativa nos leva a entender que a educação é um instrumento de poder, dependendo de quem a cria e para quem a faz, pode servir para oprimir, ou para libertar.

De acordo com Brandão, ao fazer a crítica da educação capitalista, Freire tentava desarmá-la da ideia de que ela é superior ao ser humano. Fazer diluir essa ideia de que as pessoas são um produto da educação; e florescer a compreensão de que somos sujeitos e 
protagonistas dela. Em outras palavras, é necessário crer que, antes, determinados tipos de homens e mulheres criam determinados tipos de educação, para que, posteriormente, ela recrie determinados tipos de homens e mulheres.

Para Lutero quanto mais pessoas tivessem acesso à educação melhor seria para a sociedade. Ter acesso aos estudos, sobretudo, aos textos bíblicos possibilitaria aos homens e mulheres uma relação direta com o seu criador sem depender da mediação de nenhuma autoridade eclesiástica. Acessar diretamente as Sagradas Escrituras e poder interpretá-las cunhava uma relação mais livre e autônoma entre o crente e Deus no sentido de uma autodeterminação; liberdade de tutela das mediações na relação com Deus; atuação social como cidadãos de caráter, honestidade e de ajuda aos pobres. No dizer de Lutero, "fluem da fé o amor e a paixão por Deus, e do amor flui uma vida livre, disposta e feliz, para servir ao próximo gratuitamente" (2017, p. 185). A lógica cristã defendida por Lutero era a lógica do apóstolo Paulo: “de graça recebestes, de graça deveis dar". A vida livre surge do conhecimento da Palavra e para conhecê-la é necessário passar pela educação.

Enquanto Freire parte da leitura/problematização do mundo para a palavra, Lutero parte da Palavra para a leitura de mundo. Embora, partam de pólos distintos para interpretar a realidade, ambos potencializam a ação e participação do indivíduo como agente transformador. Pois, quem ler e interpreta o mundo, senão o indivíduo? Da mesma forma, quem ler e interpreta as Escrituras Sagradas, senão o indivíduo? Vale salientar a preocupação desses pensadores com a criação de métodos educacionais que viessem a favorecer a criatividade e a formação dos indivíduos. Que não ficassem na mera memorização ou na repetição de conteúdos. Mas, que os conteúdos vivenciados por educadores e educandos fossem pertinentes para a vida, atravessem os sujeitos, dando-lhes sentido à existência, à convivência social e à presença no mundo.

\section{APROXIMAÇÕES DIALÓGICAS E COMPLEMENTARIDADES}

Algumas categorias em Lutero e em Freire apontam para aproximações e complementaridades, é o que se compreende, por exemplo, sobre liberdade/autonomia. Aproximações porque ambos abarcam os conceitos de liberdade e autonomia enquanto 
ascendência do indivíduo, isto é, superação de uma condição de opressividade, na qual se encontra o indivíduo. Complementaridade no quesito que, para Lutero, o indivíduo livre/autônomo é aquele que não se deixa aprisionar pelo condicionamento dogmático, a liberdade cristã parte de uma aderência interna (autodeterminação) do indivíduo em direção à vontade divina, aqui se justifica a livre interpretação das Sagradas Escrituras, enquanto instrumento de efetivação do potencial humano, pois, todos/as temos o livre acesso a Deus, mediante a compreensão do sacerdócio comum dos fiéis. Ademais, a superação do próprio sistema medieval burocrático e institucional notado quando o Reformador evidencia a valorização da ampliação das estruturas, modos de participação e do livre pensamento de caráter individual (doutrina da justificação pela fé e a compreensão do sacerdócio universal dos fiéis).

Para Freire, a autonomia é também um ato de superação dos dogmas, principalmente, no que tange à compreensão de verdade absoluta na ciência positiva, mas é também o exercício permanente da criticidade, que valoriza a espontaneidade, criatividade e a organização social, a ponto dos sujeitos sociais questionarem e transformarem a ordem sociopolítica vigente. Autonomia no sentido de empoderamento e de consideração do potencial humano, antes visto e entendido como mero aprendiz, agora deixa de ser objeto para ser protagonista da sua aprendizagem, da sua história (FREIRE, 1996). Nessa perspectiva, é possível que o/a educador/a aprenda junto ao seu/a educando/a.

E, naturalmente avanços, pois Freire fala do estado emancipatório dos sujeitos a partir de um contexto político-pedagógico. Essa emancipação é materializada numa compreensão de práxis pedagógica (ação movida à reflexão e reflexão gerando ação). Desse modo, os sujeitos emancipados tomam consciência dessa autonomia, e em coletividade lutam pela emancipação de outros sujeitos e pela quebra de paradigmas tradicionais opressores.

Outro elemento que, nessa relação dialógica, fica evidente é o elemento da humanização, entendida enquanto perspectiva ético-política, de engajamento consciente dos sujeitos (Freire) e enquanto perspectiva ético-religiosa, de engajamento com a vivência da Palavra (Lutero). 
A humanização em Freire tem a ver com o processo de transitividade da consciência, quando o sujeito deixa para trás a consciência ingênua e ressurge por meio de uma consciência crítico-reflexiva, possibilitadora de diálogo com a realidade humana e históricosocial. A humanização em Lutero ganha forma quando o indivíduo encarna o Evangelho enquanto proposta de vida nova, de libertação, mas de encontro consigo mesmo e com irmãos (fraternidade). Desta feita, o processo de letramento/alfabetização engendrado por Lutero tem a finalidade de humanização, pois, por meio da educação cristã, homens e mulheres novos/as construirão uma sociedade mais harmoniosa e solidária.

Tanto a educação luterana, quanto a educação freireana, compreende o processo formativo enquanto via de humanização dos sujeitos. Quando se fala que a proposta é educar o indivíduo de maneira integral se pensa numa educação que forme para a vida, que desenvolva a criticidade e os posicionamentos éticos para o enfrentamento desses sujeitos em meio às suas realidades sociais. Sendo assim, essa educação não pode se dá desapegada do contexto sociopolítico em que se encontram os educandos/as, mas é atrelada a essas realidades do educando/a que a educação ganha força enquanto ação social de transformação humana.

A universalidade da educação é mais um ponto convergente entre as pedagogias de Lutero e a de Freire. Propor e lutar por uma educação universal, pública e obrigatória são princípios defendidos por ambos os pensadores. É possível perceber como preocupação tanto de Lutero como de Freire a construção de uma educação popular, voltada às populações empobrecidas, privadas do direito ao saber e ao conhecer. Nesse sentido, tanto a perspectiva de educação luterana bem como freireana compreende a aproximação entre indivíduo e sociedade/mundo. Ademais, uma educação para todos/as, em que meninos e meninas possam usufruir dos mesmos direitos, embora com funções e destinos distintos na educação luterana (LUTERO, 2000).

A práxis pedagógica observada mediante as concepções de educação em Lutero e em Freire assume intencionalidades formativas com acentos diferentes e aproximativos. Quanto a Lutero, este não atentou, naturalmente, para a compreensão de uma formação em conjunto, mas inovou quando em seu método educativo considerou a brincadeira enquanto atividade 
pedagógica, levando em conta a espontaneidade e os contextos culturais dos educandos/as, fazendo do estudo um momento prazeroso, significativo e de utilidade para vida, objetivando, inclusive, a formação dos novos agentes da sociedade; Com relação a Freire, percebemos a compreensão, propriamente dita, de práxis enquanto ação-reflexão-ação, uma prática pedagógica coligada a uma ação social coletivizada e consciente, propulsora de humanização e emancipação. Assim, enquanto Lutero articula uma ação pedagógica voltada para o funcional/situacional, Freire propõe uma ação pedagógica direcionada a transformar as estruturas sociais, de modo particular, aquelas de natureza opressora.

\section{CONSIDERAÇÕES}

Portanto, as questões abordadas, a partir do acesso às literaturas: luterana e freireana, de um modo geral, aguçam a nossa curiosidade epistêmica em torno da compreensão dos sentidos presentes na práxis pedagógica desenvolvida por sujeitos aprendentes e ensinantes das diversas ambiências educativas, sobretudo, a não-escolar.

Os resultados oriundos da relação dialógica entre as pedagogias de Lutero e de Freire apontaram para uma tessitura de vida, conhecimento e emancipação no percurso formativo dos sujeitos envolvidos com a proposta de educação que articula as práticas dos dois autores.

A tecelagem apontada fora construída de modo coletivo e intencional, a partir das leituras de mundo e das vivências pedagógicas. Assim, os processos de humanização e emancipação demonstram os constructos aprendentes e, simultaneamente, circunscreve a missão formadora das pedagogias luterana e freireana.

\section{REFERÊNCIAS}

BRANDÃO, C. R. O que é educação. Col. Primeiros Passos. nº. 20, São Paulo: Brasiliense, 2013.

CALADO, A. J. Paulo Freire: sua visão de mundo, de homem e de sociedade. Caruaru: Edições FAFICA, 2001.

CAMBI, F. História da pedagogia. São Paulo: UNESP, 1999. 
FREIRE, P. Pedagogia da Autonomia: saberes necessários à prática educativa. São Paulo: Paz e Terra, 1996.

Educação e mudança. Trad. de Moacir Gadotti e Lillian Lopes Martin. 31.ed. Rio de Janeiro: Paz e Terra, 2008.

JARDILINO, J. R. L. Lutero e educação. Coleção Pensadores e Educação. Belo Horizonte: Autêntica Editora, 2009.

LUTERO, M. Educação e reforma. São Leopoldo: Sinodal; Porto Alegre: Concórdia, 2000. Coleção Lutero para hoje.

. Martinho Lutero: uma coletânea de escritos. São Paulo: Vida Nova, 2017.

REZENDE, Antonio Muniz de. Concepção fenomenológica da educação. São Paulo: Cortez, 1990.

SAVIANI, D. História das idéias pedagógicas no Brasil. 4. ed. Campinas: Autores Associados, 2013.

SOUZA, J. F. de. Prática pedagógica e formação de professores. Ensaio para concorrer ao cargo de professor. UFPE, Recife, 2006.

Submetido em: $19 / 12 / 2018$

Aprovado em: 06/02/2019 